\begin{tabular}{|c|c|c|c|c|}
\hline Share: Social Work Jurnal & VOLUME: 8 & NOMOR: 2 & HALAMAN: $142-149$ & $\begin{array}{c}\text { ISSN: 2339-0042 (p) } \\
\text { ISSN: 2528-1577 (e) } \\
\text { Doi: } 10.24198 / \text { share.v8i2.18885 }\end{array}$ \\
\hline
\end{tabular}

\title{
MEKANI SME MASYARAKAT LOKAL DALAM MENGENALI BENCANA DI KABUPATEN GARUT
}

\author{
Meilanny Budiarti Santoso ${ }^{1}$, Ahmad Buchari², I van Darmawan ${ }^{3}$ \\ ${ }^{1}$ Program Studi Kesejahteraan Sosial, Fakultas I Imu Sosial Dan IImu Politik, Universitas Padjadjaran \\ meilanny.budiarti@unpad.ac.id \\ ${ }^{2}$ Program Studi Administrasi Publik, Fakultas IImu Sosial Dan I Imu Politik, Universitas Padjadjaran \\ ahmad.buchari@unpad.ac.id \\ ${ }^{3}$ Program Studi IImu Pemerintahan, Fakultas I Imu Sosial Dan I Imu Politik, Universitas Padjadjaran \\ van.idevice@gmail.com
}

\begin{abstract}
ABSTRAK
Kabupaten Garut merupakan salah satu kabupaten di provinsi J awa Barat, yang dikenal masyarakat sebagai kawasan "mini market" bencana di Indonesia, sehingga layaknya masyarakat berupaya untuk dapat hidup selaras dengan berbagai potensi bencana alam yang ada dan memiliki kemampuan untuk meningkatkan kapasitas dalam menghadapi bencana. Memahami mekanisme masyarakat lokal dalam mengenali bencana adalah langkah awal yang perlu dilakukan untuk dapat menciptakan sistem mitigasi bencana berbasis masyarakat. Metode penelitian yang digunakan adalah deskriptif analisis dan pendekatan kualitatif dengan sumber data primer dan sekunder melalui teknik wawancara mendalam dan validasi data dilakukan dengan triangulasi sumber. Hasil penelitian menunjukkan masyarakat Kabupaten Garut memiliki mekanisme dalam mengenali potensi terjadinya bencana, yaitu dengan menemukenali berbagai gejala yang terjadi sesuai dengan jenis bencana yang berpotensi terjadi. Kepercayaan, pengetahuan, kesadaran dan perilaku yang dimiliki oleh masyarakat lokal merupakan asset, terutama dalam upaya pencegahan terjadinya bencana (mitigasi bencana). Namun demikian, terkait kepercayaan dan ritual yang dulu dilakukan oleh masyarakat sebagai upaya pencegahan bencana, saat ini mulai luntur dan ditinggalkan karena dinilai bertentangan denagn keyakinan agama mayoritas yang dianut oleh masyarakat setempat.
\end{abstract}

Kata kunci: mitigasi bencana, kearifan lokal, pengetahuan lokal, desa tanggap bencana

\begin{abstract}
Garut Regency is one of the districts in the province of West Java, which is known to the public as a "mini market" area of disasters in Indonesia, so that people like to try to live in harmony with the various potential natural disasters that exist and have the capacity to increase capacity in dealing with disasters. Understanding the mechanisms of local communities in recognizing disasters is the first step that needs to be done to create a community-based disaster mitigation system. The research method used is descriptive analysis and qualitative approaches with primary and secondary data sources through in-depth interview techniques and data validation is done by triangulating sources. The results showed that the people of Garut Regency had a mechanism in recognizing the potential for disasters, namely by identifying various symptoms that occur according to the type of disaster that has the potential to occur. Trust, knowledge, awareness and behavior owned by local communities are assets, especially in efforts to prevent disasters (disaster mitigation). However, related to the beliefs and rituals that were once carried out by the community as a disaster prevention effort, nowadays it has begun to fade and be abandoned because it is considered to be contrary to the majority religious beliefs adopted by the local community.
\end{abstract}

Keywords: disaster mitigation, local wisdom, local knowledge, disaster response village 


\begin{tabular}{|c|c|c|c|c|}
\hline Share: Social Work Jurnal & VOLUME: 8 & NOMOR: 2 & HALAMAN: $142-149$ & $\begin{array}{c}\text { ISSN: 2339-0042 (p) } \\
\text { ISSN: 2528-1577 (e) } \\
\text { Doi: } 10.24198 / \text { share.v8i2.18885 }\end{array}$ \\
\hline
\end{tabular}

\section{PENDAHULUAN}

Secara kondisi geografis, Indonesia merupakan negara kepulauan yang tepat terletak pada posisi pertemuan empat lempeng tektonik, yaitu lempeng Benua Asia, lempeng Benua Australia, lempeng Samudera Hindia dan lempeng Samudera Pasifik. Pada bagian selatan dan timur, secara geografis di Indonesia terdapat sabuk vulkanik ( vulkanic arc) yang memanjang di mulai dari Pulau Sumatera - Nusa Tenggara - Sulawesi, dan sisanya berupa pegunungan vulkanik tua dan dataran rendah yang sebagian besar didominasi oleh rawa-rawa. Kondisi yang demikian sangat berpotensi sekaligus rawan untuk terjadinya bencana seperti letusan gunung berapi, gempa bumi, tsunami, banjir dan tanah longsor (Bappenas, 2006).
Berdasarkan Data Informasi Bencana Indonesia (DIBI)-BNPB, terlihat bahwa lebih dari 1.800 kejadian bencana di Indonesia pada periode tahun 2015 hingga tahun 2015 lebih dari 78\% (11.648) kejadian bencana merupakan bencana hidrometrologi dan sekitar 22\% (3.810) kejadian merupakan bencana geologi. Kejadian bencana yang dikelompokkan ke dalam bencana hidrometerologi adalah bencana berupa kejadian banjir, gelombang ekstrim, kebakaran lahan dan hutan, kekeringan, dan cuaca ekstrim. Sedangkan kelompok bencana geologi yang sering terjadi di Indonesia berupa gempa bumi, tsunami, letusan gunung api dan tanah longsor. Kecenderungan jumlah kejadian bencana tersebut secara total untuk kedua jenis kelompok bencana tersebut relative terus meningkat. Hal tersebut seperti tampak pada grafik 1 di bawah ini:

Grafik 1

J umlah Kejadian Bencana di Indonesia Tahun 2005 -2015

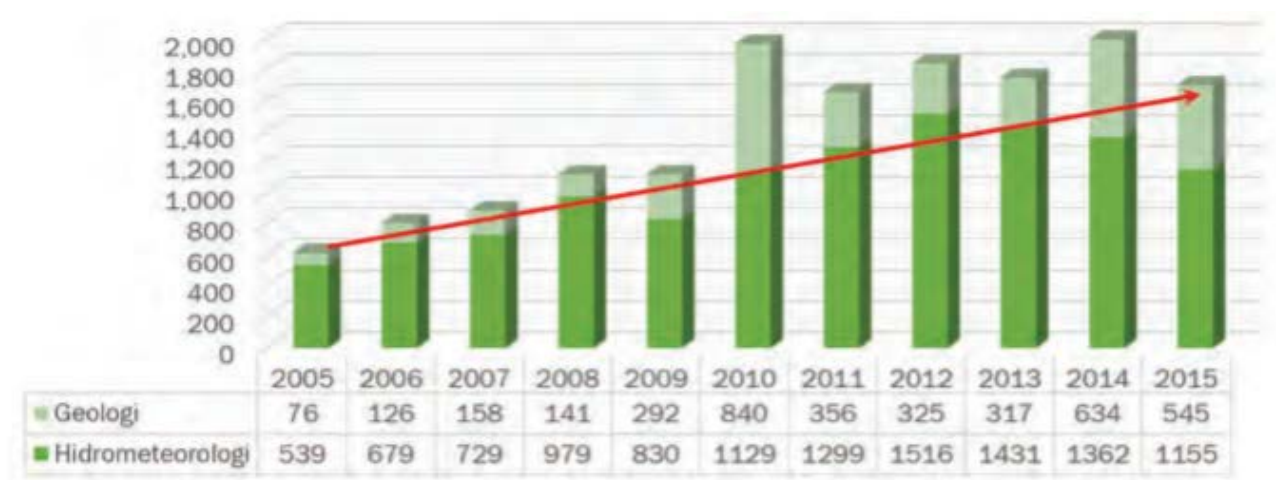

Sumber: Diolah dari BNPB, 2016

Sepanjang tahun 2017 berdasarkan data Badan Nasional Penanggulangan Bencana (BNPB), telah terjadi bencana di Indonesia sebanyak 2.175 kejadian yang terdiri dari: bencana banjir sebanyak 737 kali, putting beliung 651 kali, tanah longsor 577 kali, kebakaran hutan dan lahan 96 kali, banjir dan tanah longsor 67 kali, kekeringan 19 kali, gempa bumi 18 kali, gelombang pasang / abrasi 8 kali serta letusan gunung api sebanyak 2 kali. Dengan demikian, 95\% kejadian bencana di Indonesia digolongkan ke dalam bencana hidrometeorologi, yaitu bencana yang dipengaruhi oleh kondisi cuaca, seperti: longsor, kekeringan, putting beliung, kebakaran hutan dan lahan, dan karena cuaca ekstrem (Suryowati, 2017).

Kerawanan terjadinya bencana di Indonesia secara geologis memiliki potensi yang besar, khususnya pada beberapa bagian wilayah yang berada pada jalur patahan lempeng Eurasian (Asia, Pasifik dan Australia) dan garis circumstance, yaitu garis potensi bencana gunung berapi yang membentang di sepanjang Asis, Pasifik dan Amerika yang melewati daerah Indonesia (Wikantiyoso, 2010).

Salah satu upaya untuk menanganai kebencanaan yang telah ditempuh oleh pemerintah Indonesia melalui Badana Nasional Penanggulangan Bencana (BNPB) adalah dengan melakukan pembentukan kelembagaan Desa Tangguh Bencana (destana), yaitu agar masyarakat ditingkat desa mampu melakukan manajemen bencana dalam menghadapi potensi bencana serta mampu untuk meminimalisasi potensi kerugian yang diakibatkan oleh bencana (Buchari dkk., 2017). Hal ini merupakan upaya mitigasi bencana yaitu salah satu cara atau tindakan untuk mengurangi kerugian akibat bencana, sehingga dapat diperkecil.

Berdasarkan Keputusan Menteri Dalam Negeri RI No. 131 tahun 2003 Tentang Pedoman 
Penanggulangan Bencana dan Penanganan Pengungsi di Daerah, bahwa mitigasi adalah upaya yang dilakukan untuk mengurangi akibat-akibat yang ditimbulkan oleh bencana yang meliputi kesiapsiagaan dan kewaspadaan dalam menghadapi bencana.

Pengembangan Program Desa/Kelurahan Tangguh Bencana juga sejalan dengan visi Badan Nasional Penanggulangan Bencana (BNPB), yaitu: "Ketangguhan Bangsa dalam Menghadapi Bencana." Masyarakat yang tangguh ialah masyarakat yang mampu mengantisipasi dan meminimalisasi kerusakan, melalui adaptasi. Mereka juga mampu mengelola dan menjaga struktur dan fungsi dasar tertentu di dalam masyarakat ketika terjadi bencana. Apabila terkena dampak bencana, masyarakat akan dengan cepat bisa membangun kehidupannya kembali untuk menjadi normal atau paling tidak dapat dengan cepat memulihkan diri secara mandiri melalui mekanisme yang berkembang di dalam masyarakat.

Kabupaten Garut sebagai salah satu kabupaten di provinsi J awa Barat, merupakan "mini market" terjadinya bencana di Indonesia. Hal tersebut sejalan dengan data Badan Pusat Statistik terkait jumlah bencana alam menurut jenis bencana di Kabupaten Garut pada Tahun 2017 sebagai berikut:

Tabel 1

J umlah Bencana Alam Menurut J enis Bencana di Kabupaten Garut Tahun 2017

\begin{tabular}{|c|c|c|c|c|c|c|}
\hline & Kecamatan & $\begin{array}{l}\text { Banjir } \\
\text { flood }\end{array}$ & $\begin{array}{c}\text { kebakaran } \\
\text { Burning }\end{array}$ & $\begin{array}{c}\text { Tanah } \\
\text { longsor } \\
\text { Lands/ide }\end{array}$ & $\begin{array}{c}\text { Angin } \\
\text { topan } \\
\text { Hurricane }\end{array}$ & $\begin{array}{c}\text { lain-lain } \\
\text { Others }\end{array}$ \\
\hline & (1) & (2) & (3) & (4) & (5) & (6) \\
\hline 1 & Cisewu & & 2 & 2 & 3 & \\
\hline 2 & Caringn & & 3 & & 1 & \\
\hline 3 & Talegong & & 1 & 3 & & \\
\hline 4 & Bungbulang & & 4 & 2 & 1 & \\
\hline 5 & Mekarmukti & & 4 & & & \\
\hline 6 & Pamulihan & & 1 & 3 & 2 & Gempa Bumi 1 Kali \\
\hline 7 & Pakenjeng & & 4 & 1 & 2 & \\
\hline 8 & Cikelet & & 4 & & & \\
\hline 9 & Pameungpeuk & & 2 & & 1 & Gempa Bumi 1 Kali \\
\hline 10 & Cibalong & & 5 & & 1 & Gempa Bumi 1 Kali \\
\hline 11 & Cisompet & & 5 & 4 & & Gempa Bumi 1 Kali \\
\hline 12 & Peundey & & 1 & 4 & & \\
\hline 13 & Singajaya & & 2 & 1 & 1 & \\
\hline 14 & Cihurip & & & 1 & 1 & Gempa Bumi 1 Kali \\
\hline 15 & Cikajang & & 1 & & & Gempa Bumi 1 Kali \\
\hline 16 & Banjarwangi & & & 7 & 1 & Gempa Bumi 1 Kali \\
\hline 17 & Cilawu & 1 & 1 & 6 & & Gempa Bumi 1 Kali \\
\hline 18 & Bayongbong & & 5 & 2 & & \\
\hline 19 & Cigedug & & 2 & & & \\
\hline 20 & Cisurupan & & 3 & 1 & & \\
\hline 21 & Sukaresmi & 2 & 3 & & 3 & \\
\hline 22 & Samarang & & 9 & & & \\
\hline 23 & Pasirwangi & & 5 & & & \\
\hline 24 & Tarogong Kidul & 4 & 12 & & & Gempa Bumi 1 Kali \\
\hline 25 & Tarogong Kaler & & 7 & & & \\
\hline 26 & Garut Kota & 1 & 6 & & 2 & \\
\hline 27 & Karangpawitan & & 3 & 1 & 2 & Gempa Bumi 1 Kali \\
\hline 28 & Wanaraja & & 1 & & & \\
\hline 29 & Sucinaraja & & 2 & & & \\
\hline 30 & Pangatikan & 0 & 0 & 0 & 0 & \\
\hline 31 & Sukawening & 0 & 0 & 0 & 0 & \\
\hline 32 & Karangtengah & & 1 & & & \\
\hline 33 & Banyuresmi & & 1 & & 2 & \\
\hline
\end{tabular}




\begin{tabular}{|l|l|l|l|l} 
Share: Social Work Jurnal & VOLUME: 8 & NOMOR: 2 & HALAMAN: $142-149$ & $\begin{array}{c}\text { ISSN: 2339-0042 (p) } \\
\text { ISSN: 2528-1577 }(e) \\
\text { Doi: } 10.24198 / \text { share.v8i2.18885 }\end{array}$ \\
\hline
\end{tabular}

\begin{tabular}{|c|c|c|c|c|c|c|}
\hline \multicolumn{2}{|r|}{ Kecamatan } & $\begin{array}{l}\text { Banjir } \\
\text { flood }\end{array}$ & $\begin{array}{c}\text { kebakaran } \\
\text { Burning }\end{array}$ & $\begin{array}{c}\text { Tanah } \\
\text { longsor } \\
\text { Landslide }\end{array}$ & $\begin{array}{c}\text { Angin } \\
\text { topan } \\
\text { Hurricane }\end{array}$ & $\begin{array}{c}\text { lain-lain } \\
\text { Others }\end{array}$ \\
\hline 34 & Leles & 1 & 8 & 2 & 1 & \\
\hline 35 & Leuwigoong & & 5 & & & \\
\hline 36 & Cibatu & & 2 & & & Gempa Bumi 1 Kali \\
\hline 37 & Kersamanaah & & 1 & & & \\
\hline 38 & Cibiuk & & 1 & & 2 & \\
\hline 39 & Kadungora & & 7 & & 1 & \\
\hline 40 & Blubur Limbangan & & 2 & & & \\
\hline 41 & Selaawi & & 2 & & & \\
\hline 42 & Malangbong & 1 & 3 & 1 & & \\
\hline & Jumlah & 10 & 131 & $\overline{41}$ & 27 & 11 Kecamatan \\
\hline
\end{tabular}

Sumber: Badan Pusat Statistik Kabupaten Garut, 2018

Berdasarkan data tersebut, maka selayaknya masyarakat Kabupaten Garut berupaya untuk dapat hidup selaras dengan berbagai potensi bencana alam yang ada, sehingga dalam situasi dan kondisi yang demikian masyarakat kabupaten Garut khususnya harus mampu membangun dan meningkatkan kapasitas mereka dalam menghadapi bencana. Terlebih pada saat bencana belum terjadi, yaitu dengan melakukan upaya mitigasi bencana.

Usaha mitigasi bencana dapat dilakukan pada saat prabencana, saat bencana dan pasca bencana. Prabencana berupa kesiapsiagaan atau upaya pemberdayaan dengan memberikan pemahaman kepada masyarakat untuk mengantisipasi bencana melalui pemberian informasi, peningkatan kesiagaan apabila terjadi bencana, langkah-langkah yang harus dilakukan untuk memperkecil resiko akibat bencana. Pada saat kejadian bencana yaitu berupa tanggap darurat dengan upaya yang dapat dilakukan adalah sesegera mungkin melakukan penanganan pada saat kejadian bencana, hal ini ditujukan untuk menanggulangi dampak yang akan ditimbulkan dari bencana, terutama berupa penyelamatan korban, harta benda, evakuasi dan pengungsian. Pada saat pasca bencana, mitigasi yang dilakukan adalah berupa pemulihan rehabilitasi dan pembangunan (Maryani, 2008).

Selain membangun kelembagaan secara formal, upaya mitigasi bancana pun dapat dilakukan dengan meningkatkan kapasitas masyarakat lokal dalam mengenali potensi bencana yang mungkin terjadi. Dalam pemahaman yang lebih luas dan lebih mendalam pengetahuan dan nilai-nilai budaya lokal tersebut dikenal dengan istilah kearifan lokal. Namun demikian, mitigasi bencana berbasis kearifan budaya lokal belum secara optimal tersebar luas di dalam kehidupan bermasyarakat. Hal ini seperti temuan penelitian Maryani (2008), menyimpulkan bahwa penyebab tidak optimalnya mitigasi bencana adalah rendahnya pemahaman/pengetahuan masyarakat tersebut.

Pengetahuan lokal suatu masyarakat yang hidup di lingkungan wilayah yang spesifik biasanya diperoleh berdasarkan pengalaman yang diwariskan secara turun temurun. Hal tersebut sejalan dengan pandangan Johnson dalam Sunaryo dan Joshi (2003), bahwa pengetahuan lokal adalah sekumpulan pengetahuan yang diciptakan oleh sekelompok masyarakat dari generasi ke generasi berikutnya yang hidup menyatu dan selaras dengan alam sekitarnya, pengetahuan seperti ini berkembang dalam lingkup lokal, menyesuaikan dengan kondisi dan kebutuhan masyarakat lokal.

Kajian tentang kearifan lokal dan mitigasi bencana pada masyarakat tradisional di Indonesia sejatinya terlihat dalam kaitannya dengan keberadaan sumber daya alam dan sumber daya manusia (Permana dkk., 2011). Pada masyarakat tradisional (lokal) manusia dan alam adalah satu kesatuan karena keduanya merupakan ciptaan Yang Maha Kuasa. Alam dan manusia diyakini sama-sama memiliki roh. Alam bisa menjadi ramah jika manusia memperlakukan secara arif dan sebaliknya akan bisa marah jika kita merusaknya. Umumnya, masyarakat lokal beranggapan bahwa lingkungan di sekitarnya ada yang memiliki dan menghuni selain manusia. Oleh karena itu, manusia yang berdiam di sekitarnya harus menghormati dan menjaga tempat mereka itu, seperti hutan, gunung, lembah, dan sumber air. Bahkan tidak sedikit tempat-tempat tersebut dijadikan tempat yang sakral atau dikeramatkan (Darmanto, 2009: 136; Adimihardja, 2009: 81; Boedhihartono, 2009: 67; Purwanto, 2009: 230). 


\begin{tabular}{|c|c|c|c|c|}
\hline Share: Social Work Jurnal & VOLUME: 8 & NOMOR: 2 & HALAMAN: $142-149$ & $\begin{array}{c}\text { ISSN: 2339-0042 (p) } \\
\text { ISSN: 2528-1577 (e) } \\
\text { Doi: } 10.24198 / \text { share.v8i2.18885 }\end{array}$ \\
\hline
\end{tabular}

\section{METODE}

Penelitian di lapangan dilakukan dengan menggunakan metode deskriptif analisis dan pendekatan kualitatif, yaitu agar peneliti dapat mendalami berbagai hal terkait mekanisme masyarakat lokal dalam mengenali bencana khususnya di wilayah Kabupaten Garut. Data diperoleh dari data primer sebagai data hasil wawancara bersama berbagai pihak terkait konteks penelitian yang dilakukan dan data sekunder dari berbagai institusi terkait penanganan bencana di wilayah Kabupaten Garut. Teknik pengumpulan data dalam penelitian ini dilakukan dengan wawancara mendalam dan studi dokumentasi. Validasi data dilakukan dengan teknik triangulasi yaitu triangulasi sumber dengan melakukan pemeriksaan data yang sama dari berbagai sumber data yang diperoleh dan kemudian dilakukan analisis data sesuai dengan konteks penelitian.

\section{HASI L DAN PEMBAHASAN}

Memahami mekanisme masyarakat lokal dalam mengenali bencana adalah langkah awal yang perlu dilakukan apabila akan menciptakan sistem mitigasi bencana berbasis masyarakat, karena dengan mengidentifikasi mekanisme yang dikembangkan oleh masyarakat lokal dalam mengenali bencana, maka akan ditemukan bagaimana pemahaman dan kapasitas yang dimiliki oleh masyarakat untuk dapat hidup selaras dengan potensi bencana yang ada di lingkungan mereka.

Desa Pasawahan terletak di Kecamatan Tarogong Kaler Kabupaten Garut Provinsi Jawa Barat. Desa Pasawahan merupakan salah satu desa di Kabupaten Garut yang rawan untuk terjadinya bencana dari gunung api, dikarenakan letak dari Desa Pesawahan yang berada pada kaki gunung Guntur. Gunung Guntur merupakan gunung api yang masih aktif, yaitu dengan adanya aktivitas vulkanik. Gunung api Guntur juga memiliki tingkat kemiringan lereng yang curam dengan kandungan material tanah berpasir dan bebatuan. Terkait kondisi stabilitas tanah di wilayah gunung Guntur dikategorikan labil, dengan tingkat kelongsoran tanah termasuk pada kategori tinggi dan daya serap tanah yang cukup. Dengan beberapa kondisi tersebut tentunya dapat mengakibatkan desa Pesawahan menjadi salah satu desa yang rawan untuk terjadinya bencana.

Berdasarkan pengetahuan yang diturunkan dari generasi ke generasi berikutnya, masyarakat Desa Pasawahan telah mempunyai kemampuan untuk memprediksi potensi terjadinya letusan gunung api. Di antaranya adalah dengan munculnya tanda-tanda yang dapat dilihat, yaitu ketika seluruh hewan liar yang ada dan hidup di gunung mulai turun dari gunung, dan ketika suhu lingkungan tiba-tiba mengalami peningkatan.

Selain itu, perilaku masyarakat sebagai upaya pelestarian lingkungan hidup oleh pun telah menjadi sebuah kebiasaan, yaitu dengan menanam pohon ketika ada masyarakat yang hendak naik ke atas gunung, selain itu saat hendak turun gunung pun biasanya mereka menempuh jalur sungai yang ada di sana sambil membersihkan aliran sungai dari sampah-sampah, dan kegiatan tersebut dilakukan saat akan musim hujan datang.

Masyarakat desa Pasawahan yang berada di kaki gunung Guntur hingga saat ini masih memegang pada kepercayaan adat setempat yang diturunkan dari para leluhurnya. Salah satu kepercayaan tersebut adalah pemahaman yang mentabukan masyarakat untuk membunyikan alat gamelan berupa goong. Hingga saat ini masyarakat desa Pasawahan masih mempercayai bahwa pada saat mereka melakukan suatu pesta atau suatu perayaan, mereka dilarang membunyikan goong. Apabila hal tersebut dilanggar, maka berdasarkan kepercayaan masyarakat setempat, mereka akan mengalami suatu bencana.

Kepercayaan lain yang berkembang di masyarakat desa Pasawahan adalah ketika musim hujan datang, maka masyarakat memiliki mekanisme sendiri untuk menangkal terjadinya bencana banjir maupun bencana hujan angin, yaitu dengan melakukan ritual dengan memanjatkan do'a bersama dan memberikan sesajen sebagai bentuk penangkalan terjadinya bencana. Namun seiring perkembangan dan pergeseran nilai di dalam masyarakat, saat ini kegiatan ritual semacam itu mulai ditinggalkan karena dinilai bertentangan dengan ajaran agama mayoritas yang diyakini saat ini oleh masyarakat setempat.

Terlepas dari sistem penanganan bencana yang kompleks, masih terkandung beragam kearifan lokal masyarakat di Kabupaten Garut yang hingga kini masih menjadi acuan secara tradisional dalam memperkirakan terjadinya bencana dibandingkan dengan memanfaatkan teknologi terapan yang lebih modern untuk menditeksi terjadinya bencana. Kerangka pikir secara tradisional tersebut tentunya sangat berkaitan dengan kebiasaan masyarakat dalam mengamati fenomena yang terjadi secara berulang, yang kemudian menjadi karakteristik model manajemen tanggap bencana di masyarakat secara tradisional. 


\begin{tabular}{|c|c|c|c|c|}
\hline Share: Social Work Jurnal & VOLUME: 8 & NOMOR: 2 & HALAMAN: $142-149$ & $\begin{array}{c}\text { ISSN: 2339-0042 (p) } \\
\text { ISSN: 2528-1577 (e) } \\
\text { Doi: } 10.24198 / \text { share.v8i2.18885 }\end{array}$ \\
\hline
\end{tabular}

Hal tersebut tercermin seperti halnya yang diungkapkan oleh Buchari, dkk (2017) bahwa masyarakat di Desa Mekarjaya Kecamatan Cikajang Kabupaten Garut telah menggunakan teknik pengamatan terhadap tingkat kekeruhan air sungai sebagai alat ukur yang akan mengindikasikan terjadinya bencana banjir di hulu sungai. Begitupun dengan masyarakat di wilayah Desa Karyamekar yang lebih mempercayai fenomena pergerakan tanah secara kasat mata dibandingkan dengan menggunakan teknologi sirine sebagai pertanda akan terjadi longsor di wilayah tersebut.

Lebih jauh, masyarakat Desa Mekarjaya dan Desa Karyamekar mengungkapkan bahwa alasan paling kuat mengapa mereka lebih memilih untuk menggunakan pendekatan tradisional yang berlandaskan pada pengetahuan dan pengalaman masyarakat lokal dibandingkan dengan pendekatan yang menggunakan teknologi canggih adalah karena masyarakat menilai bahwa pendekatan tradisional lebih efektif dan akurat dalam memberikan sinyal bagi masyarakat apabila akan terjadinya bencana.

Tentunya pandangan tersebut didukung oleh pengalaman nyata masyarakat terhadap kegagalan teknologi canggih dalam memberikan informasi terjadinya bencana, seperti yang terjadi di Kecamatan Tarogong Kaler yaitu pada suatu hari masyarakat dihebohkan dengan bunyi sirine sebagai tanda akan meletusnya gunung Guntur. Seketika setelah sirine berbunyi, banyak masyarakat Kecamatan Tarogong Kaler yang diungsikan, begitupun dengan tempat-tempat wisata di kawasan Cipanas Garut segera ditutup dengan alasan untuk menjaga keamanan. Namun, ternyata setelah beberapa waktu berlalu, gunung Guntur tidak meletus, sehingga masyarakat beranggapan bahwa teknologi canggih dan modern tidak dapat memberikan informasi yang akurat bagi mereka.

Pengalaman demikian pun dirasakan oleh masyarakat Desa Karyamekar yang menyatakan bahwa teknologi canggih tidak lebih efektif dibandingkan dengan pengamatan pergerakan tanah yang secara langsung dilakukan oleh masyarakat, ataupun melalui pengamatan terhadap curah hujan. Dalam hal ini, masyarakat Desa Karyamekar memiliki pengalaman pernah dikejutkan oleh bunyi sirine tanda bahaya akan terjadinya longsong. Namun, ternyata di daerah yang terindikasi akan terjadi longsor pada saat itu tidak terjadi.

Berdasarkan berbagai data dan informasi yang ditemukan di lapangan, menunjukkan bahwa manusia mempunyai kapasitas untuk dapat menyerap dan memahami apa yang terjadi di sekelilingnya, selanjutnya menganalisa dan menafsirkan baik sebagai hasil pengamatan maupun pengalaman mereka, yang pada gilirannya dapat digunakan untuk meramalkan atau pun sebagai dasar dalam pertimbangan mereka untuk proses pengambilan keputusan. Dengan demikian, pengetahuan merupakan keluaran dari proses pembelajaran, penjelasan berdasarkan pemikiran dan persepsi yang terbentuk dalam mekanisme bermasyarakat dan berinteraksi dengan lingkungan alam mereka.

Pengetahuan praktis tentang ekosistem lokal, sumber daya alam dan bagaimana mereka saling berinteraksi akan tercermin baik di dalam kehidupan sosial masyarakatnya maupun pada keterampilan masyarakat dalam mengelola sumber daya alam yang tersedia. Pengetahuan lokal yang sudah sedemikian menyatu dengan sistem kepercayaan, norma dan budaya diekspresikan di dalam tradisi dan norma yang dianut dalam jangka waktu yang lama. Hal inilah yang kemudian kita kenal sebagai kearifan lokal.

Faktanya tidak semua mekanisme yang biasa dilakukan oleh masyarakat baik itu berupa pengetahuan, kebiasaan, dan juga keterampilan dapat dirasionalkan dengan menggunakan ilmu pengetahuan. Hal ini adalah bagian dari pengetahuan lokal (local knowledge) yang perlu terus diteliti, diselidiki dan dikembangkan agar masyarakat semakin meningkat kapasitasnya dalam menemukenali potensi terjadinya bencana yang sewaktu-waktu dapat terjadi.

Situasi dan kondisi masyarakat yang sudah modern seperti dewasa ini, di mana masyarakat telah mengalami banyak perubahan dan perkembangan seiring perubahan zaman, dengan lebih banyak mengedepankan ilmu pengetahuan dan tidak lagi memahami kearifan lokal yang ada pada masyarakat terdahulu; Lebih mengedepankan pemenuhan kebutuhan ekonomi dibandingkan dengan menjaga keseimbangan alam; Lebih memprioritaskan alasan-alasan rasional dibandingkan dengan memegang nilainilai keyakinan yang diturunkan oleh generasi sebelumnya. Tentunya situasi dan kondisi masyarakat yang demikian sangat bertentangan dengan pandangan yang diungkapkan oleh Darmanto (2009), Adimihardja (2009), Boedhihartono (2009) dan Purwanto (2009) yang menggambarkan masyarakat tradisional (lokal) manusia dan alam adalah satu kesatuan karena keduanya sama-sama ciptaan Yang Maha Kuasa; Alam dan manusia diyakini sama-sama memiliki 


\begin{tabular}{|c|c|c|c|c|}
\hline Share: Social Work Jurnal & VOLUME: 8 & NOMOR: 2 & HALAMAN: $142-149$ & $\begin{array}{c}\text { ISSN: 2339-0042 (p) } \\
\text { ISSN: 2528-1577 (e) } \\
\text { Doi: } 10.24198 / \text { share.v8i2.18885 }\end{array}$ \\
\hline
\end{tabular}

roh, sehingga manusia yang berdiam di sekitarnya harus menghormati dan menjaga tempat mereka, seperti hutan, gunung, lembah, dan sumber air; Bahkan tidak sedikit tempat-tempat tersebut dijadikan tempat yang sakral atau dikeramatkan. Kontradiksi tersebut tentunya secara alamiah akan mendatangkan akibat ditengah hubungan antara manusia dengan alam, yaitu terjadinya 'kemarahan' alam berupa bencana.

Oleh karena itu, diperlukan upaya untuk mengembangkan dan menguatkan pengetahuan serta keterampilan masyarakat lokal dalam mengenali datangnya bencana sebagai bentuk mitigasi bencana yang berkembang di tengah masyarakat, bahkan menjadi kebutuhan yang sangat sangat penting untuk dilakukan dengan melibatkan berbagai stakeholder terkait dalam mitigasi bencana.

Secara lebih luas, diperlukan upaya identifikasi berbagai mekanisme yang telah berkembang di masyarakat dalam mengenali potensi terjadinya bencana, sehingga dapat dikembangkan model mitigasi bencana yang tepat sesuai dengan pengetahuan dan mekanisme yang sudah berkembang di dalam masyarakat lokal. Hal ini sejalan dengan pandangan Maskud (2016) yang menyatakan bahwa masyarakat di daerah rawan bencana pada umumnya sudah mempunyai sistem peringatan dini yang bersifat lokal, walaupun belum terstruktur.

\section{SI MPULAN DAN SARAN}

Masyarakat Kabupaten Garut memiliki mekanisme tersendiri dalam mengenali potensi terjadinya bencana, yaitu dengan menemukenali berbagai gejala yang terjadi sesuai dengan jenis bencana yang berpotensi terjadi. Kepercayaan, pengetahuan, kesadaran dan perilaku yang dimiliki oleh masyarakat lokal merupakan asset bagi masyarakat setempat, terutama dalam upaya pencegahan terjadinya bencana (mitigasi bencana).

Pengetahuan masyarakat lokal mengenai perilaku alam, hewan dan pergerakan konstruksi alam tertentu dipahami sebagai bentuk-bentuk perilaku alam yang memberikan sinyal bagi masyarakat lokal bahwa akan terjadinya bencana dan hal-hal tersebut lebih dipercaya dan diyakini kebenarannya oleh masyarakat setempat bila dibandingkan dengan menggunakan peralatan canggih sebagai alat peringatan bencana.

Adapun kepercayaan terdahulu yang diyakini dan dibudayakan oleh masyarakat lokal melalui berbagai bentuk ritual kepercayaan, dewasa ini mulai luntur dan ditinggalkan oleh masyarakat karena dinilai bertentangan denagn keyakinan agama mayoritas yang dianut oleh masyarakat setempat.

Dengan demikian, masyarakat lokal Kabupaten Garut perlu didorong untuk terus ditambah pengetahuan dan keterampilannya dalam mengenali potensi terjadinya bencana, diperbaiki sikap dan perilakunya dalam berinteraksi dengan alam di sekitarnya, dan ditingkatkan kesadaran dan kapasitasnya untuk menghadapi ancaman alam di sekitarnya. Hal ini mengingat Kabupaten Garut merupakan kawasan yang dikenal sebagai 'mini market' bencana di Indonesia. Untuk dapat mewujudkan berbagai harapan dalam meningkatkan kapasitas masyarakat tersebut, haruslah didukung oleh pemerintah mulai dari tingkat pusat hingga tingkat daerah dan adanya sinergitas dengan berbagai stakeholder terkait lainnya.

\section{DAFTAR PUSTAKA}

Adimihardja, K. (2009). Leuweung titipan: Hutan Keramat Warga Kasepuhan di Gunung Halimu. Dalam Herwasono Soedjito et al. (Penyunting), Situs Keramat Alami. J akarta: Yayasan Obor Indonesia, Komite Nasional MAB Indonesia, LIPI dan Conservation International Indonesia, 7885.

Amri, M.R., Yulianti, G., Yunus, R. Wiguna, S., Adi A.W., Ichwana, A.N., Randongkir R. E., Septian, R.T. (2016). Risiko Bencana Indonesia (RBI). BNPB

Ataupah. 2004. Peluang Pemberdayaan Keraifan Lokal Dalam Pembangunan Kehutanan. Kupang: Dephut Press.

Badan Nasioanl Penanggulangan Bencana. (2017). Info Bencana Desember 2016. Diakases tanggal 1 Agustus 2017 dari https://www.bnpb.go.id/uploads/publicati on/ info_bencana_desember_final.pdf.

Bappenas dengān BKNPB. (2006). Rencana Aksi Nasional Pengurangan Risiko Bencana 2006-2009. Jakarta: Badan Perencanaan Pembangunan Nasional Press.

Boedhihartono (2009). Tanah Toa, Kajang, Bulukumba, Sulawesi Selatan. Dalam H. Soedjito et al. (Eds), Situs Keramat Alami. J akarta: Yayasan Obor Indonesia, Komite Nasional MAB Indonesia, LIPI dan Conservation International Indonesia, 6277.

Buchari, A., Santoso, M. B., \& Marlina, N. (2017). Pengembangan Kapasitas Kelembagaan 


\begin{tabular}{|c|c|c|c|c|}
\hline Share: Social Work Jurnal & VOLUME: 8 & NOMOR: 2 & HALAMAN: $142-149$ & $\begin{array}{c}\text { ISSN: 2339-0042 (p) } \\
\text { ISSN: 2528-1577 (e) } \\
\text { Doi: 10.24198/share.v8i2.18885 }\end{array}$ \\
\hline
\end{tabular}

Desa Tanggung Bencana di Kabupaten Garut (Studi Kasus Di Desa Pasawahan Kecamatan Tarogong Kaler). Jurnal Analisis dan Kebijakan Publik. Vol. 3 No. 1. J uni 2017. HIm. 49-62

Darmanto. (2009). Pandangan tentang Hutan, Tempat Keramat, dan Perubahan Sosial di Pulau Siberut, Sumatera Barat. Dalam Herwasono Soedjito et al. (Eds), Situs Keramat Alami. Jakarta: Yayasan Obor Indonesia, Komite Nasional MAB Indonesia, LIPI dan Conservation International Indonesia, 130-164.

Fauzi, H. (2006). "Memahami Fenomena Alam Pertanda Bencana". Opini dalam Banjarmasin Post, 30 September 2006.

Keputusan Menteri Dalam Negeri RI No. 131 tahun 2003 Tentang Pedoman Penanggulangan Bencana dan Penanganan Pengungsi di Daerah

Maarif, Syamsul. (2015). Sosiologi Kebencanaan dan Pengurangan Risiko Bencana Komunitas (Pengukuhan sebagai Guru Besar Sosiologi Kebencanaan). J ember: Universitas Jember

Maryani, Enok. (2008). Model Sosialisasi Mitigasi Pada Masyarakat Daerah Rawan Bencana di J awa Barat. Bandung: Penelitian HIBAH DIKTI.

Maskud. (2016). Kearifan Lokal Dalam Penanggulangan Bencana Banjir Bandang dan Tanah Longsor di Kecamatan Panti Kabupaten J ember. Fenomena, Vol. 15 No. 2. Oktober 2016

Noor, M. \& Jumberi, A. (2007). Kearifan Budaya Lokal dalam Perspektif Pengembangan Pertanian di Lahan Rawa. Banjarbaru/Bogor: Balai Besar Sumber daya Lahan Pertanian.

Permana, R.C.E., Nasution, I.P. \& Gunawijaya J. (2011). Kearifan Lokal Tentang Mitigasi
Bencana Pada Masyarakat Baduy. Makara, Social Humaniora, Vol. 15 No. 1, Juli 2011. HIm. 67-76

Purwanto, Y. (2009). Tempat Keramat Masyarakat Dani di Lembah Baliem" dalam Herwasono Soedjito dkk. (E) Situs Keramat Alami. J akarta: Yayasan Obor Indonesia, Komite Nasional MAB Indonesia, LIPI dan Conservation I nternational I ndonesia, 215239.

Stanis, Stefanus. (2005). "Pengelolaan Sumberdaya Pesisir dan Laut Melalui Pemberdayaan Kearifan Lokal di Kabupaten Lembata, Propinsi Nusa Tenggara Timur". Tesis. Tidak Dipublikasikan.

Sunaryo dan L. Joshi. (2003). Peranan Pengetahuan Ekologi Lokal dalam Sistem Agroforestri. World Agroforestry Centre (ICRAF) Southeast Asia Regional Offive, Bogor, Indonesia

Suryowati, Estu. (2018). Sepanjang 2017, BNPB Mencatat 2.175 Kejadian Bencana di Indoensia. Harian Umum Nasional Kompas. Diunduh pada 19 September 2018 pukul 14.05 WIB.

Wahyono, A. (2001). Pemberdayaan Masyarakat Nelayan. Yogyakarta: Media Pressindo.

Wikantiyoso, Respati. (2010). Mitigasi Bencana di Perkotaan; Adaptasi atau Antisipasi Perencanaan dan Perancangan Kota? (Potensi Kearifan Lokal Dalam Perencanaan dan Perancangan Kota Untuk Upaya Mitigasi Bencana). Local Wisdom. Vol. 2, No. 1. HIm. 18-29, J anuari 2010.

Zamzami, Lucky \& Hendrawati. (2011). Kearifan Budaya Lokal Masyarakat Maritim Untuk Upaya Mitigasi Bencana Di Sumatera Barat. Padang: Lembaga Penelitian Universitas Andalas. 